\title{
GRAPH MODEL FOR MINIMAL DISTANCE AND OPTIMAL CIRCULATION IN URBAN DESIGN
}

\author{
Pingkan S. Pioh ${ }^{1)}$ \\ ${ }^{1)}$ Faculty of Engineering, Manado State University, Tondano, Indonesia \\ e-mail: pingkanpioh@yahoo.com
}

\begin{abstract}
Among the important aspects in urban design are minimal distance and optimal circulation of the traffic network which include good access to the places of interests. The main road network is modeled in graph where the important places are represented by vertices and the main roads between them are represented in edges. A graph is called 3-connected if for every pair of vertices, there are three disjoint paths connecting them. Given the vertices and their locations, this paper focuses to make a 3-connected graph with minimal distance connecting them. This model is simulated in a computer program and applied in a current road network of Manado City, North Sulawesi Indonesia to see whether of not the road network in Manado is already optimal or not.
\end{abstract}

Keywords: graph, $n$-connected, minimal distance, urban design.

\section{MODEL GRAF UNTUK JARAK MINIMAL DAN SIRKULASI OPTIMAL PADA PERANCANGAN KOTA}

\begin{abstract}
ABSTRAK
Diantara aspek penting dalam perancangan kota adalah jarak yang minimal dan sirkulasi yang baik dari lalu lintas termasuk aksesibilitas dari tempat-tempat penting. Perancangan ini dimodelkan dalam bentuk graf yang simpul-simpul mewakili tempat-tempat penting sedangkan sisi-sisi menyajikan jalan-jalan yang menghubungkan tempat-tempat tersebut. Sebuah graf dikatakan terkoneksi-3 jika untuk setiap pasangan simpul, terdapat 3 jalur saling lepas yang menghubungkan kedua simpul itu. Fokus dari paper ini adalah, jika diberikan simpul-simpul bersama lokasinya, membuat graph yang terkoneksi-3 dengan jarak minimal. Model ini diimplementasikan dalam bentuk program komputer dan diterapkan pada jaringan jalan yang ada di Manado, Sulawesi Utara, Indonesia, sekarang untuk menentukan apakah jaringan jalan di Manado sudah optimal atau belum.
\end{abstract}

Kata kunci: Graf, terkoneksi-3, jarak minimal, perancangan kota.

\section{INTRODUCTION}

One of the problems of the most big cities is traffic jam. This is mainly caused by bad design of road network. The traffic jam usually happens in the intersections of public facilities. If one section gets blocked by crowded traffic, there should be alternative ways to out some of the traffic. In other words, the connectivity of the network should be high enough.

In Architectural layout especially in urban design is particularly interesting because in addition to common engineering objectives such as cost and performance. Spatial configuration is concerned with finding feasible locations and for a set of interrelated objects that meet all design requirements and maximize design quality in terms of design preferences. So the good design must be an optimal design, and the optimal design can provide the good recommendation of value engineering.

Among the main considerations in designing a city are circulation and short in distance of transportation system. Circulation means that the traffic should keep going smoothly. This implies that when one of the roads is paralyzed perhaps because of accident, traffic jam, or anything else, then there should be an alternative road that is capable to take the rerouting traffic; in other words there should be enough alternative routes from one place to another.

The distance will effect in cost of the construction of the roads and also the gas 
consumption of traffic. It is clear that the shorter the distance, the lower the cost.

To model the architecture layout of urban design, especially the transportation network, graph can be used. Graph is a pair of set of vertices and set of edges. The set of vertices can represent the places of important destinations which include public facilities such as government offices, shopping centers, universities, etc., and the set of edges can represent the roads connecting the places.

From a mathematical point of view, a graph $G$ is a pair $(V, E)$, where $V$ is a nonempty finite set of elements, called vertices, and $E$ is a finite family of two elements sets of elements of $E$, called edges. If $u$ and $v$ are vertices and $u v$ is an edge, then $u$ and $v$ are adjacent. A road from a place $u$ to a different place $w$ with intermediate places is then indicated with a path, that is a sequence of vertices is $u v_{1} v_{2} v_{3} \ldots v_{k} w$ where $v_{1}, v_{2}, v_{3}, \ldots$, $v_{k}$ are intermediate places. Then two different routes from place $u$ to $w$ can be transformed into two disjoint paths between $u$ and $w$. If every pair of vertices, there are three disjoint paths connecting them, then the graph is called 3-connected.

Given the locations of the places represented by vertices, the distances between the locations can be measured or computed. Hence given two vertices connected by different paths, the shortest distance among the paths can be determined, and so the total distance among all possible paths.

This paper provides a 3-connected graph model with minimal distance of a road network given some points of areas of interests. A computer program is developed to simulate this. Finally, the program is applied to the current road network in Manado, North Sulawesi, Indonesia.

\section{GRAPH THEORY AND URBAN DESIGN}

A graph $G=(V, E)$ is a pair of a finite nonempty set of objects called vertices (the singular is vertex) together with (possible empty) set of unordered pair of vertices of $G$ called edges. The vertex set of $G=(V, E)$ is denoted by $V(G)$, while the edge set is denoted by $E(G)$ (Chartrand and Lesniak, 1996).
The edge $e=\{v, w\}$ is said join the vertices $v$ and $w$; in this case, $v$ and $w$ are said to be adjacent vertices, while $e$ and $v$ are incident, as are $e$ and $w$. Furthermore, if $e_{1}$ and $e_{2}$ are distinct edges of graph $G$ with a common vertex, the $e_{1}$ and $e_{2}$ are adjacent edges. It is convenient to henceforth denote an edge by $v w$ or $w v$ rather than by $\{u, v\}$.

The cardinality of the vertex set of a graph $G=(V, E)$ is called order of $G$ and is commonly denoted $n(G)$ or $|V|$; while the cardinality of its edge set is the size of $G$ and often denoted by $m(G)$ or $|E|$.

It is customary to define or describe a graph by means of a diagram in which each vertex is represented by a point (usually drawn as a small circle) and each edge $v w$ is represented by a line segment or curve joining the points corresponding to $v$ and $w$.

With the exception of the order and the size, the parameter that one encounters most frequently in the study of graphs is the degree of a vertex. The degree of a vertex $v$ the number of edges incident with $v$, which is denoted by $\operatorname{deg}(v)$. A vertex of degree 0 is called and isolated vertex, while a vertex of degree 1 is an end-vertex. The minimum degree of a graph $G$ is the minimum degree among the vertices of $G$, and the maximum degree of graph is defined similarly.

Let $v$ and $w$ be (not necessarily distinct) vertices of graph $G$. A $v$-w walk of $G$ is a finite, alternating sequences

$$
v=v_{0}, e_{1}, v_{1}, e_{2}, v_{2} \ldots v_{k-1}, e_{k}, v_{k}=w
$$

of vertices and edges, beginning with vertex $v$ and ending with vertex $v$ such that $v_{i} v_{i+1}$ is an edge in $G$, for $i=1,2, \ldots, k$. The number $k$ (the number of occurrences of edges) is called the length of the walk. A trivial walk contains no edges, that is, $k=0$. Note that there may be repetition of vertices and edges in a walk. Often only the vertices of a walk are indicated since the edges present are then evident. Two $u-v$ walks $u=u_{0}, u_{1}, \ldots, u_{k}=v$ and $u=v_{0}, v_{1}, \ldots, v_{j}=v$ are considers to be equal if and only if $k=j$ and $u_{i}=v_{i}$ for $0 \leq i \leq$ $k$; otherwise, they are different. Observe that the edges of two different $u-v$ walks of $G$ may very well induce the same subgraph of $G$.

A $u-v$ walk is closed or open depending on whether $u=v$ or $u \neq v$. A $u-v$ trail is a $u-v$ walk in which no edge is repeated, while a $u-v$ path is a $u$-v walk in which no vertex is repeated. A vertex $u$ forms the trivial $u-u$ path. Every path is therefore a 
trail. Two paths $u \quad u_{1} u_{2} \quad \ldots \quad u_{k} w$ and $u v_{1}$ $v_{2} \ldots v_{l} w$ are disjoint, if $u_{i} \neq v_{l}$, for $1 \leq i \leq k$ and $1 \leq i \leq l$.

In the graph $G$ of Figure 2.1, $v_{2} v_{4} v_{5}$ and $v_{2} v_{6} v_{5}$ are disjoint path, but $v_{1} v_{2} v_{4} v_{5}$ and $v_{1} v_{2} v_{6} v_{5}$ are not disjoint paths.

A graph is connected if for every pair of vertices $u$ and $v$, there is a path joining them.

Menger's Theorem (Chartrand and Lesniak, 1996)..

Let $G$ be a connected graph with at least $k+$ 1 vertices. Then

(i) $G$ is $k$-connected if and only if every two vertices $\mathrm{v}$ and $\mathrm{w}$ are connected by at least $\mathrm{k}$ paths which are pairwise disjoint except for the vertices $v$ and $w$;

(ii) $G$ is $k$-edge-connected by at least $k$ edgedisjoint paths.

The Dijkstra's shortest path algorithm is to determine the shortest path between a designated vertex $v_{0}$ and each of the other vertices in a loop free connected directed graph. Dijkstra's algorithm maintains a set $S$ of vertices whose final shortest-path weights from the source $s$ hae already been determined.

The simplest way of considering the design of town or city is a tool, a place which must work efficiently and with the least possible friction. The road system of town, for example, provides one of the frameworks pattern, and it is often said that if its layout is determined by the scientific findings of road engineering, the plan must be a good one: that the first stage in town design is for engineer to plan the roads, after which the other experts can come along and carry out their particular tasks. (Gibberd, 1970).

According to Rutz (1987), the urban in Indonesia is increasing faster than the rural population. It causes that the towns and cities also grow at a faster rate than the total settlement system does.

The building of a new town is so complex and so much money is involved that it can seldom be achieved without Government backing and some special organization such as the Development Corporation which were set up to build the British new towns under the 1947 new town act (Gibberd, 1970).
Most towns today have a characteristic functional pattern, as follows: a central core, containing the principal shopping centre, civic group and business zones; surrounded by suburban of houses, often each with its own character and its with its own shopping centre and others social services; and areas of industry, some of which are often associated with the town centre and some with the railway. The pattern has become confused through towns acting as magnets to the growing industrial population.

The pattern of most towns is still valid, save only that they are subject to more rapid social and technological changes than in the past and, of these changes, a new machine, motorcar, has conflicted violently with the idea of the town as a place to be in. their preoccupation in the preparation of a master plan is with the definition of the town itself; and the designing of systems of circulation which link the town to the region.

The master plan thus has three broad patterns: a) Building group; b) Landscape; and c) Circulation.

It defines the ultimate growth of the town in relationship to the region; it lays down a pattern of urban growth related to the existing topography; and it shows the lines of movement in the static building and landscape patterns (Gibberd, 1970).

In term of circulation, it shows a network of principal roads designed as a hierarchy to serve the built-up areas and to connect those areas to each other and the region. Its show the routes of public transport, the relationship of bus and railway stations to the town centre and railway siding to industry; it will define the principal pedestrian routes about the town and their connections with traffic nodal points, such as a bus interchange station.

Jane Jacobs (1960) goes on to analyze the things which give a street that liveliness; she suggests there are three main conditions:

a. Firstly, if a street is to be safe, there must be a clear demarcation between public space and private space, between the territory which belongs to a particular house, a particular household, a particular house, a particular household, particular shop or whatever and that which belongs to all.

b. Secondly, a constant watch must be kept; the eyes of those whom Jane calls: the 
natural proprietors of the street must be scanning it all the time. Their scanning will be all the easier if the buildings which line the street are orientated towards.

c. Thirdly, the street itself and the sidewalks in particular must be in constant use. The street must actually go from one place where people want to be to another, and there must be enough attractions along the street itself for linger there.

According to Lynch (1960), several key elements come into play as we construct our images of the city, which he identified as paths, edges, districts, nodes and landmarks, which are the following:

1. Paths, the channels of movement which people take, regularly, occasionally or may, potentially, take. They may include paths, streets, walkways, bus or tram lines, canals, railways and so on. We observe the city as we are moving through it and for many people, the paths themselves, and those element of the city they perceive as they move along them predominate in their images of the city. They are the coordinate axes;

2. Edges are linear elements which people do not use as paths. They perceive them, rather, as linear breaks or boundaries of some kind. They may be physical boundaries as walls, railway cuttings, canals, shorelines, or they may simply be boundaries between adjacent developments. While not so dominant as paths such boundaries are important organizing features for many people especially when, in the form of, say, water or city wall they play the role of holding together generalized areas;

3. Districts are medium to large sections of the city which people visualize as having two dimensional extents. Not only do they form districts on the map, they are also recognizable, especially from within, as having some common, identifying character, which indeed may be so strong that one has a distinct, mental impression of entering inside of. This maybe recognizable, also from outside. Most people, according to Lynch, find this idea of district to be most important in building up their image of the city. Indeed, according to the city- and the individual perceiver - they may be more important than paths;
4. Nodes (Vertices) are strategic points within the city to or from which the observer travels. They may be crossing or convergences of paths, junctions, places where one changes from one mode of transport to another. Or they may be concentrations of some kind, which are important because of their physical form: such as urban squares, street corners. They may be condensers of particular uses. Some, nodes in fact, will be the focus and epitome of district, over which their influence radiates and of which they stand as a symbol;

5. Land mark too is reference-points but the observer does not objects such as a building, a sign, a store or even a mountain. A landmark in this sense will be a physical object which, because of its form, may be singled out from the surrounding environment. They may be large, manmade objects such as a tower, a spire or a dome, soaring over the rooftops and acting as a radial references from many points within the city.

\section{GRAPH MODEL FOR MINIMUM DISTANCE AND OPTIMAL CIRCULATION IN URBAN DESIGN}

As mentioned, among the considerations are the distances of the roads and the circulation of traffics, especially those connecting the public facilities.

It is clear that the shorter the distance, the lower the cost either to construct the roads or in term of gas consumption. In some cases, centralized of public facilities will cause problems. If all public facilities are located in one area, it will be overloaded with traffic. Therefore the public facilities may be spread in many places.

The circulation implies that in the design of road network, from one public facility to another, there should be alternative roads. This is to avoid traffic jam in case of one route is paralyzed by any cause. The more alternative routes the better for the circulation, but it will have consequences in cost of making the roads.

If the public facilities are represented by vertices and the routes are represented by edges connecting the vertices, then the public 
facilities and the routes can be represented as graphs.

The locations of the public facilities can be indicated by geometrical coordinates. Hence the distances between the two vertices can be computed as geometrical distance of two coordinates. The weight $w(e)$ of an edge $e=v w$ is the distance between the vertices $v$ and $w$.

The problem can then be formulated as follows. Given set of vertices $V$ with corresponding coordinates, determine the graph $G=(V, E)$ with its edge set $E$ such that:

- the graph is 3-connected

- the sum of all distances is minimal

Let $v$ and $w$ be vertices with coordinates respectively $\left(x_{1}, y_{1}\right)$ and $\left(x_{2}, y_{2}\right)$, the weight $\delta(e)$ of the edge $e=v w$ is the distance between $v$ and $w$, that is:

$$
\delta(e)=\sqrt{\left(x_{2}-x_{1}\right)^{2}+\left(y_{2}-y_{1}\right)^{2}} .
$$

Let $G=(V, E)$ be a graph. Then $P(G)$ is the set of all paths in $G$. If $P$ is a path in $G$, then $|P|$ is the length of the path which is defined as the number of edges in $P$. If $v$ and $w$ are vertices, and $P=v_{1} Q w_{1}$ is a path where $|Q| \geq 0$, then $v P w$ is a path in graph $G$ if $v v_{1}$ and $w_{1} w$ are edges in $G$. The path $v P w$ is called connecting $v$ and $w$.

Two paths $v P_{1} w$ and $v P_{2} w$ be two paths connecting $v$ and $w$ in graph $G$. Then $v Q_{1} w$ and $v Q_{2} w$ are said to be disjoint if $Q_{1}$ and $Q_{2}$ contain no common vertex. Two disjoint paths $P_{1}$ and $P_{2}$ denoted by $P_{1} \cap P_{2}=$ $\varnothing$. Note that a path is a sequence of vertices, but here a set operator $\cap$ is used; this may not give any confusion.

Let $G=(V, E)$ be a graph and $\delta(e)$ be the weight of $e$. Then the objective is

$$
\begin{array}{ll} 
& \operatorname{Min} \sum_{e \in E} \partial(e) \\
\text { s.t. } & \underset{v, w \in G}{\forall} \underset{P, Q, R}{\exists} v P w, v Q w, v R w \in P(G) \\
\wedge P \cap Q=\varnothing \wedge P \cap R=\varnothing \wedge P \cap R=\varnothing
\end{array}
$$

In other words,

- minimizing the total weights (minimal distance)

- subject to that for each pair of vertices $v$ and $w$, there are 3 disjoint paths connecting them (3-connected).

\section{S IMULATION BY COMPUTER PROGRAM}

The model is implemented in a computer program developed using Delphi 6.0 (Zukhri, 2003). The main algorithms used in the programs are the Dijkstra's Shortest Path Algorithm and the following algorithm for 3-connected graph:

\section{Dijkstra's Shortest Path Algorithm}

This algorithm is used to find the shortest path (based on sum of edge weights) from one vertex to another vertex.

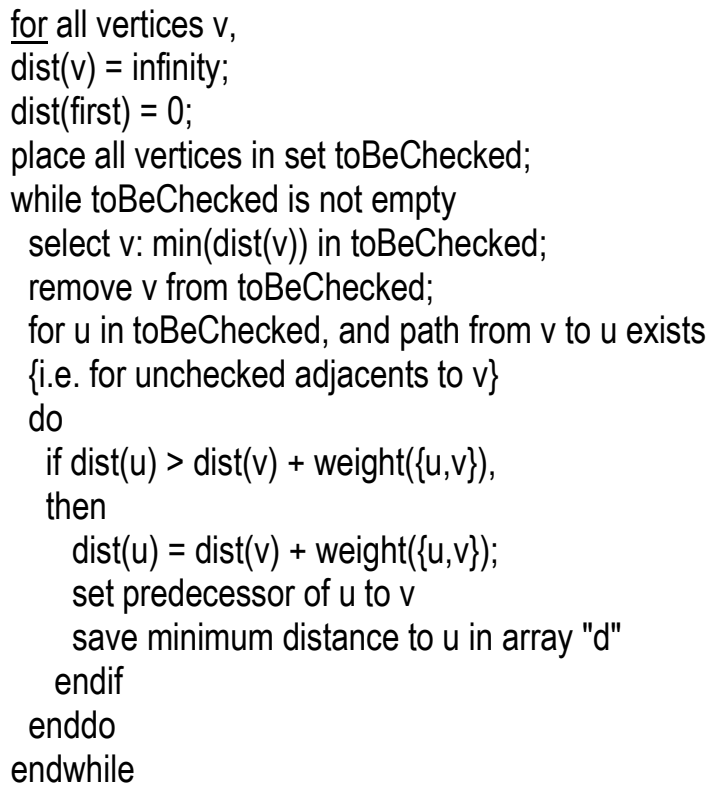

\section{3-Connected Graph}

This algorithm is used to find the 3-connected graph with minimal distance.

call optimal 2-connected graph

for $\mathrm{u}$ in vertices do while degree $(\mathrm{u})<3$ do select v: minimum weight $(\mathrm{u}, \mathrm{v})$ and there is no edge from $u$ to $v$ create an edge from $\mathrm{u}$ to $\mathrm{v}$ enddo enddo

\section{EXAMPLE: ROAD NETWORK OF MANADO}

Manado city is one of the fast growth cities, with many public places and interest buildings. This situation comes up with the increasing number of cars in the roads on the peak hour. Traffic jams occurs often in many places. 
Figure 1 shows some of the important places in Manado and Figure 2 indicates the graph representing the current network of main roads in Manado. This is obviously not 3-connected for deleting two edges will disconnect the graph.

Using the computer simulation, Figure 3 shows the input the vertices representing the important places in the computer program. The distances between vertices are calculated according to their coordinates. The optimal 3-connected solution with shortest distance is shown in figure 4 .

This shows that there must be the alternative roads with optimal circulation and optimum distance in Manado. If we in rush hour and ride transportation, we can make decisions to use the path of street that connected to objective place with minimum distance, that mean we can get the efficient in time and gas consumption of our cars.

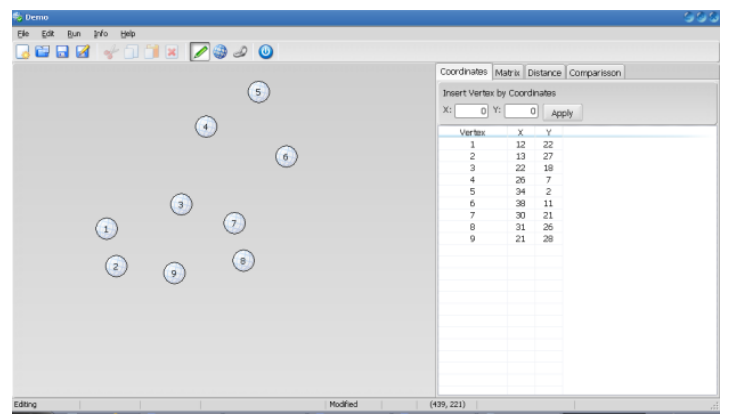

Figure 3. The input vertices in the computer program

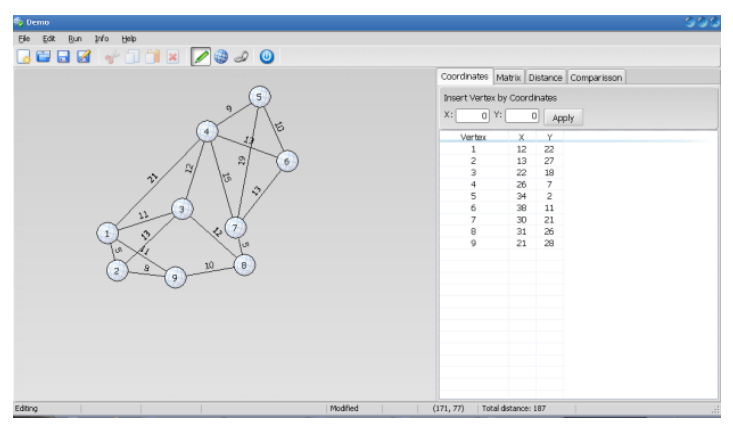

Figure 4. Optimal distance with 3connected of Manado main roads

\section{CONCLUSIONS}

The conclusions are as follows :

1. The architectural layout of urban design can be model in graph where places of interest are represented by vertices and roads connecting them are represented by edges. The distance of the roads should be minimal and the connectivity should be taken care.

2. Given of the locations of the vertices, a 3 -connected graph with minimal distance can be constructed. The minimal distance are done using Dijkstra's Shortest Path Algorithm.

3. The current main road network in Manado is not 3-connected. Some additional main roads should be added to make it 3-connected, which will reduce the traffic jam problem significantly.

\section{REFERENCES}

Bondy, J.A and U.S.R.Murty. 1976. Graph Theory with Applications. NorthHolland, Amsterdam

Chartrand, G. and L. Lesniak. 1996. Graphs and Digraphs, Third edition. Chapman \& Hall, California. Springer - Verlag, New York.

Cormen, T. H, and C. E Leiserson, Introduction to Algorithms. The MIT Press, Massachusetts and McGrawHill,New York.

Dijkstra, E.W. 1982. Selected Writings on Computings: A Personal Perspective. Springer.

Ecker, J. G and M. Kupferscmid. 1988. Introduction to Operations Research. John Wiley \& Sons, New York.

Gibberd, F. 1970. Town Design. The Architectural Press, London.

Grimaldi, R.P. 1994. Discrete and Combinatorial Mathematics, Third edition . Addison Wesley Publishing Company, Massachussetts.

Jacobs, J . 1961. The Failure of Town Planning, Penguin book, Harmondsworth.

Lynch, K. 1960. The Image of City, MIT Press, Cambridge, Mass. And London.

Rutz, W. 1987. Cities and Towns in Indonesia. Gebruder Borntraeger, Berlin.

Zukhri, Z. 2003. Dasar-dasar Pemrograman Visual dengan Delphi 6.0 Graha Ilmu, Yogyakarta. 


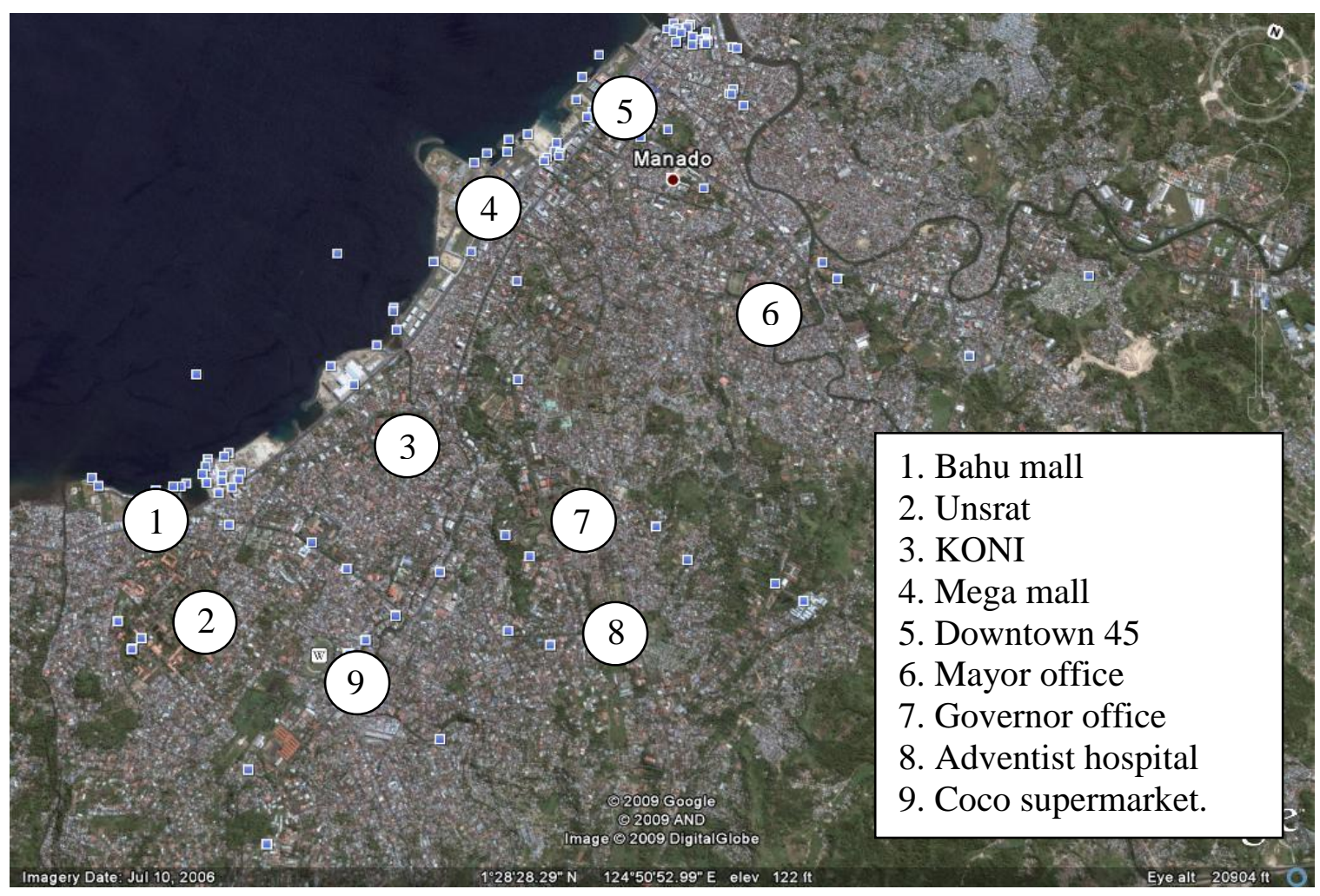

Figure 1. Locations of public places in Manado (Map source: Google Earth)

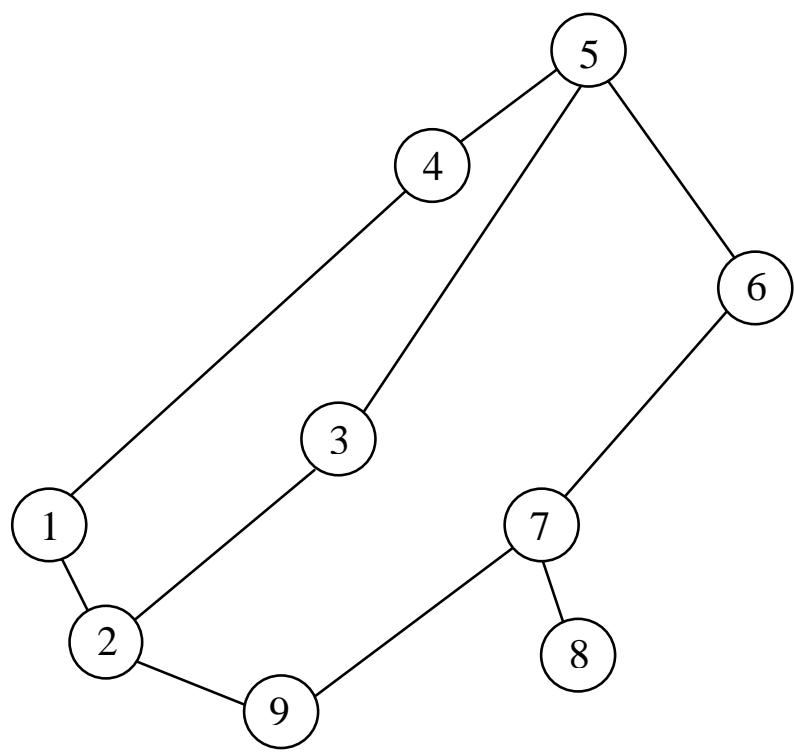

1. Bahu mall

2. Unsrat

3. KONI

4. Mega mall

5. Downtown 45

6. Mayor office

7. Governor office

8. Adventist hospital

9. Coco supermarket.

Figure 2. The network of main roads of Manado (Map source: Google Earth) 